\title{
Angina Pectoris and the Arnolds: Emotions and Heart Disease in the Nineteenth Century
}

\author{
FAY BOUND ALBERTI*
}

\section{The Case of Thomas Arnold of Rugby}

On the evening of Saturday 11 June 1842, Thomas Arnold, the educational reformer and Headmaster of Rugby school, strolled in the institutional gardens with his head boy, William Charles Lake. ${ }^{1}$ Thomas would subsequently dine with the Sixth Form boys; a customary act on the last day of term. His diary entry for that evening noted, "The day after to-morrow is my birthday, if I am permitted to see it". ${ }^{2}$ His words proved prescient. At 5 a.m. on Sunday, Thomas woke with agonizing pains across his chest. Three hours later he was dead, a victim of angina pectoris. The same disease had killed Thomas's father William Arnold, the Collector of Customs and Postmaster of the Isle of Wight. It would also kill Thomas's son, the poet Matthew Arnold. ${ }^{3}$ Each of these three generations of Arnold men diagnosed with angina pectoris died suddenly and unexpectedly: both Thomas and William were in their forties; Matthew died at sixty-five.

The death of Thomas Arnold was unusually well-publicized in nineteenth-century Britain. His last hours and minutes were recorded by Peter Mere Latham (or "Heart Latham" as he became known) in his work on heart disease, and by Arthur Penrhyn Stanley, a student of Thomas Arnold and later dean of Westminster. Stanley was commissioned by Mary Arnold to write her dead husband's biography. ${ }^{4}$ In Latham's account, Thomas is termed "T.A." and discussed as one of three anonymous individuals who died of angina pectoris. Latham's work includes a detailed transcription of Thomas's last conversation with his attending physician, Dr Bucknill junior.

\begin{abstract}
(C) Fay Bound Alberti 2008
*Fay Bound Alberti, PhD, Department of History, Lancaster University. Address for correspondence: Wellcome Trust Centre for the History of Medicine at UCL, 183 Euston Road, London NW1 2BE, UK.

I gratefully acknowledge the financial support of the Wellcome Trust. I would also like to thank Sam Alberti, Hal Cook, Stephen Jacyna, Christopher Lawrence, John Pickstone and Charles Rosenberg for their advice and comments on an earlier draft of this work. This article forms part of my broader research into emotions and the heart entitled Matters of the heart: locating emotions in medical and cultural history (Oxford University Press, forthcoming).

\footnotetext{
${ }^{1}$ On William Charles Lake (1817-1897), later
} dean of Durham, and on Thomas Arnold (1795-1842),
\end{abstract}

see Oxford Dictionary of National Biography, Oxford University Press, 2004 (hereafter $O D N B$ ), vol. 32, pp. 249-50, and vol. 2, pp. 501-7.

${ }^{2}$ Arthur Penrhyn Stanley, Life of Thomas Arnold, D.D. Headmaster of Rugby (1844, repr. London, John Murray, 1904), p. 655.

${ }^{3}$ On Matthew Arnold (1822-1888) see $O D N B$, vol. 2, pp. 487-94.

${ }^{4}$ Peter Mere Latham, Lectures on subjects connected with clinical medicine, comprising diseases of the heart, 2 vols, London, Longman, Brown, Green and Longmans, 1845-1846, vol. 2, p. 373-6; Stanley, op. cit., note 2 above, p. 655. Latham began his medical studies at St Bartholomew's Hospital and at the Public Dispensary in Carey Street, London. In 1815 he was elected physician to Middlesex Hospital; in 1824 he resigned this post to become physician at St Bartholomew's Hospital. See ODNB, vol. 32, pp. 624-5. 


\section{Fay Bound Alberti}

When examined, Thomas told Dr Bucknill that his own father had died of heart disease, and, apparently aware of the severity of his condition, asked whether this was usually fatal. When Bucknill replied in the affirmative, Thomas asked whether heart disease had become "a common disease". Bucknill replied that it was not very common, but increasingly prevalent in large towns, "perhaps from anxiety and eager competition among the higher, and intemperance among the lower classes". 5 Bucknill's judgment about the increasing incidence of heart disease (particularly among urban populations) was consistent with intensified medical and popular interest in the study of the heart and its diseases. ${ }^{6}$

There was a growing belief in nineteenth-century Britain that heart disease was on the increase. This belief encouraged, and developed from, a relatively new interest in cardiac medicine as a clinical specialism, with the emergence of specifically qualified physicians and hospitals, and an apparent rise in heart disease as a cause of death. ${ }^{7}$ In 1872 , for instance, The Times reported that male deaths from heart disease had risen from 5,746 in 1851 to 12,428 in 1870 . This shift was linked to the "working years of active social life" and particularly affected men aged twenty to forty-five years. ${ }^{8}$ In an interesting parallel with modern medical practice, nineteenth-century heart disease was therefore gendered towards men. ${ }^{9}$ Part of this increase, The Times article maintained, resulted from the "great mental strain and hurried excitement of these times, in an overcrowded community, where competition is carried to the highest point". ${ }^{10}$ This was not the first time that an increase in heart disease had been linked to "mental strain and excitement". In 1806 Jean Nicolas Corvisart, personal physician to Napoleon Bonaparte, claimed that there were more deaths "from the organic affections of the heart" than from "those of the lesion of the brain, stomach, liver, spleen, kidneys \&c. taken together". Part of the reason, Corvisart claimed, was the fall-out of the French Revolution, a period that saw unprecedented levels of national and individual anxiety. There were therefore, Corvisart continued, two principal reasons for a contemporary growth in diseases of the heart: "the action of the organ" and "the passions of men". 11

In an exploration of these links between heart disease and the "passions of men", this article critiques and contributes to a growing body of historical work on the medical history of the heart. ${ }^{12}$ In recent years, certain key works have identified a nineteenth-century

\footnotetext{
${ }^{5}$ Latham, op. cit., note 4 above, vol. 2, p. 375

${ }^{6}$ The previous century saw many anatomical developments in England, in the work of Matthew Baillie, William and John Hunter, and in France with Xavier Bichat, Gaspard Laurent Bayle and Jean Nicolas Corvisart. See Russell C Maulitz, Morbid appearances: the anatomy of pathology in the early nineteenth century, Cambridge University Press, 1987.

${ }^{7}$ See Christopher Lawrence, 'Moderns and ancients: the 'new cardiology' in Britain, 1880-1930', in W F Bynum, Christopher Lawrence and Vivian Nutton (eds), The emergence of modern cardiology, Med. Hist., Supplement No. 5, London, Wellcome Institute for the History of Medicine, 1985; Kirstie Blair, Victorian poetry and the culture of the heart, Oxford, Clarendon Press, 2006.

${ }^{8}$ The Times, 25 March 1872, p. 7. For another contemporary account of the rise of heart disease, see
}

also Herbert Davies, Lectures on the physical diagnosis of the diseases of the lungs and heart, London, John Churchill, 1851, pp.1-2.

${ }^{9}$ This provides an interesting contrast to the literary depiction of heart disease, which at least one scholar has identified as gendered towards women. Blair, op. cit., note 7 above, p. 37. For an account of the gendering of heart disease in the modern age, see Gerdi Weidner, Mária S Kopp and Margareta Kristenson (eds), Heart disease: environment, stress and gender, NATO Science Series, Series I, vol. 327, Amsterdam and Oxford, IOS Press, 2002.

${ }^{10}$ The Times, op. cit., note 8 above, p. 7.

${ }^{11}$ Jean Nicolas Corvisart, An essay on the organic diseases and lesions of the heart and great vessels, trans. Jacob Gates (1806), facs. repr. New York, Hafner, 1962, pp. 27.

${ }^{12}$ The etymological meanings of "passions" and "emotions" are not addressed here. By the time of 


\section{Emotions and Heart Disease in the Nineteenth Century}

transformation in medical theories about cardiac function. These include Kirstie Blair's analysis of the poetics of the heart as both organ and symbol in Victorian literature; Christopher Lawrence's path-breaking descriptions of the emergence of cardiology as a medical specialism; and Charles F Wooley's detailed account of the emergence of "nervous heart" syndrome, identified within the United States' military. ${ }^{13}$

What is missing in these accounts is a systematic analysis of the role of emotions in the diagnoses, prognoses and treatment of heart disease in general, and angina pectoris in particular. As this article demonstrates, the emotions were not incidental, but integral to the medical understandings of heart disease. Using records of Thomas Arnold's premature death as a point of access into the historical construction of angina pectoris in nineteenthcentury medical culture, this article has three aims. Firstly, it demonstrates that emotions were central to the heart and its diseases in nineteenth-century medical discourse, largely as a result of long-established interconnections between psyche and soma. By acknowledging this tradition we can identify the problematic nature and relationship of organic and functional disease concepts, depending as they do on broader interpretations of the mind and body relation. For emotions were crucial components in the conception of cardiac symptoms as "functional" or "structural" (or organic) in origin. ${ }^{14}$ Quite simply, emotions were perceived as capable of impacting on the body at both a structural level-in contributing to arterial deterioration, for example- and a functional level, by causing palpitations. This gave a considerable—often spiritual—weight to the emotions as conduits between mind and body, spirit and matter.

A second, connected claim made here is that historiographical accounts of structural and functional disease are often over-simplistic, largely because they derive from a modernist perspective. ${ }^{15}$ The history of angina pectoris does not readily conform to the model of heart disease identified by Wooley, in which (to put it crudely) diseases were identified as functional until such time as sufficient diagnostic tools existed to label them as structural. ${ }^{16}$ Throughout the nineteenth century there was much flexibility and conflict over the relationship between psychological and physical causation, and between the symptoms of structural and functional disease. The two were never mutually exclusive or independent. It

Corvisart's writing, the two terms were used interchangeably. For a discussion of the history of "passions" and "emotions" as concepts, see Thomas Dixon, 'Patients and passions: languages of medicine and emotion, 1789-1850', in Fay Bound Alberti (ed.), Medicine, emotion and disease, 1700-1950,

Basingstoke, Palgrave Macmillan, 2006, pp. 22-52.

${ }^{13}$ Blair, op. cit., note 7 above; Lawrence, op. cit., note 7 above; idem, " Definite and material": coronary thrombosis and cardiologists in the 1920s', in Charles E Rosenberg and Janet Golden (eds), Framing disease: studies in cultural history, New Brunswick, NJ, Rutgers University Press, 1992, pp. 51-82; Christopher Lawrence, Rockefeller money, the laboratory, and medicine in Edinburgh, 19191930, University of Rochester Press, 2005; Charles F Wooley, The irritable heart of soldiers and the origins of Anglo-American cardiology: the US Civil War
(1861) to World War I (1918), Aldershot, Ashgate 2002.

${ }^{14}$ To clarify, I use the term "functional" throughout this paper in the sense employed by Wooley, to "describe disorders of function of an organ or system without an obvious pathological lesion". By contrast, "structural" heart disease refers to disorders that correlated with structural changes identified at autopsy. See Wooley, op. cit., note 13 above, p. 65. The explicit association of "functional" disease with emotional excess and neuroses was not made, as argued below, until the late nineteenth century.

${ }^{15}$ See Christopher Crenner, Private practice in the twentieth-century medical office of Dr Richard Cabot, Baltimore, Johns Hopkins University Press, 2005, and the review by Christopher Lawrence, 'Dr Cabot and Mr Hyde', Med. Hist., 2006, 50: 247-51.

${ }^{16}$ See Wooley, op. cit., note 13 above, p. 67. 


\section{Fay Bound Alberti}

is, therefore incorrect to state, as Blair has done, that "functional" was "the opposite of 'organic' [disease]" in nineteenth-century medicine. ${ }^{17}$

Finally, this article follows Charles Rosenberg, John Harley Warner and others in emphasizing the evidence of medical therapeutics, instead of accepting the relevance of medical theory. ${ }^{18}$ In examining the experience and treatment of Thomas Arnold, and the recommendations of Latham, we find that the heart was not regarded as a unitary organ, nor subject to the advances in pharmacology and technology that we have come to associate with the "scientific" and rational nineteenth-century medical tradition. ${ }^{19}$ Instead, we find the continuation and preservation of eighteenth-century medical practice. Along with many others of his generation, Latham maintained an holistic interpretation of cardiac disease that emphasized links between the heart, the emotions, the blood, and the entire circulatory system.

In exploring these three areas, this article is structured as follows. It begins with an examination of the status of heart disease in nineteenth-century culture, and its apparent increase as a result of the stresses of modern life. It acknowledges the historiographical difficulties in accessing lived emotions in past times and cultures before establishing the historical relevance of emotions for medical understandings of heart disease. It argues that this background is necessary in order to comprehend the complexities of functional and structural heart disease by the nineteenth century. From established links between emotions and heart disease, this article moves to the identification of angina pectoris in the eighteenth century as a highly specific (and emotionally implicated) form of heart disease. Challenging historiographical discussions of the origins of angina pectoris it shows how this condition was always linked with both structural disease and excessive emotions, and that structural and functional disease concepts were interchangeable until the late nineteenth century. This takes issue with the modernist emphasis of much historical work on heart disease and with historians' tendency to oversimplify concepts of functional disease by linking it to twentieth-century concepts of neuroses. Many of these claims are concretized by the concluding sections of this article, when we return to Thomas Arnold, and to the therapeutic practices governing heart health, mind and body.

\section{Emotions and Heart Disease in History}

The psychological state of Thomas Arnold prior to his death is regrettably unknown. Along with the subject of heart disease-a persistent spectre in the life of Matthew

\footnotetext{
${ }^{17}$ Blair, op. cit., note 7 above, p. 30.

${ }^{18}$ Charles E Rosenberg, 'Body and mind in nineteenth-century medicine: some clinical origins of the neurosis construct', Bull. Hist. Med., 1989, 63: 185-97; John Harley Warner, The therapeutic perspective: medical practice, knowledge, and identity in America, 1820-1885, Cambridge, MA, and London, Harvard University Press, 1986.

${ }^{19}$ Lawrence, op. cit., note 7 above; Robert G Frank, 'The tell-tale heart: physiological instruments, graphic methods and clinical hopes, 1854-1914', in William Coleman and Frederick L
}

\author{
Holmes (eds), The investigative enterprise: \\ experimental physiology in nineteenth-century \\ medicine, Berkeley and Los Angeles, University of \\ California Press, 1988, pp. 211-90. For a recent \\ critique of the traditional story of nineteenth-century \\ medical development as increasingly reductionist \\ and technologically defined, see Christopher \\ Lawrence and George Weisz, 'Medical holism: the \\ context', in Christopher Lawrence and George \\ Weisz (eds), Greater than the parts: holism in \\ biomedicine, 1920-1950, New York and Oxford, \\ Oxford University Press, 1998, pp. 1-22.
}




\section{Emotions and Heart Disease in the Nineteenth Century}

Arnold - it has received surprisingly little attention in biographical work on the family. ${ }^{20}$ There is, moreover, little evidence that Thomas was anxious about his health until the day before his fatal attack, when he experienced some chest pain before and after bathing. ${ }^{21}$ Thomas did acquire during his lifetime a reputation for unrelentingly hard mental work, however, and at least one historian has suggested that his daughter's deep depression when her engagement ended contributed to Thomas's subsequent heart problems. ${ }^{22}$ The association of emotional strain with heart disease, particularly in chronic states like "stress", has resonance today. ${ }^{23}$ In common with many other diseases - including cancer-heart disease has become a "disease of civilization", a product (as suggested in The Times article cited above), of the peculiar demands of modern life. ${ }^{24}$

There is clearly no doubt that in the nineteenth century emotions were regarded as important to heart health. Yet unravelling the meanings of emotions in history is far from straightforward. The emergence of a history of emotions-paralleling interest in emotions in such disciplines as psychology, sociology, literary theory-has characterized recent historiographical developments. ${ }^{25}$ With it has come the recognition that it is no longer possible to homogenize emotional responses and experiences across time and cultures. Such formalized concepts as "stress" and "anxiety" need to be historically situated and understood according to the prevailing cultural and political milieux. ${ }^{26}$ Historical descriptions of emotions can be found in a variety of places, from court records to diaries. Yet the meanings of affect in medical textbooks on the heart can be frustratingly elusive. Outside such etymologically traceable terms as "anxiety" lurks an emotion history in which specific experiences like "grief" or "anger" are referred to obliquely, or as part of a more amorphous range of somatic and psychological concepts referred to (by Corvisart, for instance) simply as "passions". Part of the reason for this vagueness in medical history is that the term "passions" has traditionally been used as a blanket definition for emotion as opposed to reason: what precise passions were invoked was not as relevant in medicine as it was for philosophical rhetoric. ${ }^{27}$

Another possible reason why the specificities of emotional response were largely unexplored by medical writers is the boundaries of medical enquiry. Until the nineteenth-century emergence of the mind sciences, and such disciplines as psychiatry and psychology,

\footnotetext{
${ }^{20}$ Meriol Trevor, The Arnolds: Thomas Arnold and his family, London, Bodley Head, 1973; Nicholas Murray, A life of Matthew Arnold, London, Hodder and Stoughton, 1996; Park Honan, Matthew Arnold: a life, London, Weidenfeld \& Nicolson, 1981.

${ }^{21}$ Except where noted the following account is derived from Stanley, op. cit., note 2 above, pp. 655-6. See also Trevor, op. cit., note 20 above, p. 45 .

${ }^{22}$ Trevor, op. cit., note 20 above, p. 45.

${ }^{23}$ Stephen Stansfeld and Michael Marmot (eds), Stress and the heart: psychosocial pathways to coronary heart disease, London, BMJ Books, 2002. As noted below, it is important to be aware of the historical specificity of concepts like "stress". For an introduction, see Rhodri Hayward, 'Stress', Lancet, 2005, 365: 2001.

${ }^{24}$ See Mark Harrison and Michael Worboys (eds), A disease of civilisation: tuberculosis in Britain,
}

Africa and India, 1900-39, London, Routledge, 1997. For a contemporary perspective, see Benjamin Richardson, Diseases of modern life, London, Macmillan, 1876, p. 120.

${ }^{25}$ See the discussion and review in Fay Bound Alberti, 'Introduction: Medical history and emotion theory', in Bound Alberti (ed.), op. cit., note 12 above, pp. xiii-xxviii.

${ }^{26}$ Cary L Cooper and Philip Dewe, Stress: a brief history, Oxford, Blackwell, 2004; Fay Bound, 'Keywords in the history of medicine: anxiety', Lancet, 2004, 363: 1407.

${ }^{27}$ Dixon, op. cit., note 12 above, and idem, From passions to emotions: the creation of a secular psychological category, Cambridge University Press, 2003. 


\section{Fay Bound Alberti}

discussions of emotion were embedded in philosophical and theological theories. In disease diagnosis and prognosis before that time, there was a general and uncritical recognition of mental and bodily symbiosis. As Rosenberg has observed in another context, early modern physicians did not bother to explain "theologically perilous distinctions among soul, mind and soma"; they concentrated on "elucidating the presumed interaction between body and mind, emotions and physiological dysfunction, internal and external environment". ${ }^{28}$ It was taken for granted that emotions impacted on the body in a variety of means, that they could cause a variety of diseases, and that those diseases - as in the case of melancholia —included both psychological maladies, and physical infirmities. In the main, such theorizing was conceived in terms of the soul's interaction between the mind and the body, with the "spirits" or the "humours" acting as mediators. ${ }^{29}$

We need to examine some of these assumptions that were derived from classical precedent. For how could emotions affect the heart? And why was the belief that they could so enduring, the Galenic model lasting well into the nineteenth century? ${ }^{30}$ Before we consider the links between the heart and the emotions (and the specificities of angina pectoris) in Victorian Britain, we need to take a longue durée approach to the history of emotional holism. As demonstrated below, much early modern theory found its way into nineteenthcentury therapeutics. Since the classical period, an individual's emotional temperament was seen to affect his or her physical constitution, an association reinforced by humoral theory - with its emphasis on the distribution of humours around the body-from the second to the seventeenth century. In this fluid-based model, emotions mediated between mind and body, acting with the consent and assistance of the soul, and with a distinct set of ethical motivations. ${ }^{31}$ The heart played a crucial role in humoral physiology as the agent for heating, and the site where blood was attracted or repelled, according to the requirements of the experienced passion (hot blood was needed for anger, for instance, cold blood for sadness). The heart could also be damaged by excessive heat or cold, which is one of the reasons why emotional extremes were potentially fatal. ${ }^{32}$

Unsurprisingly, given the mortal danger of excess passion, physicians like John Fothergill (1712-1780) advised an avoidance of "any vehement emotions". For "excesses of passion and anxiety ... contribute more to the increase of [heart disease] than a combination of all the other causes". 33 Like the rest of the "non-naturals"- those

\footnotetext{
${ }^{28}$ Rosenberg, op. cit., note 18 above, p. 186.

${ }^{29}$ On mind and body interaction prior to the nineteenth century, see Fay Bound Alberti, 'Emotions in the early modern medical tradition', in Bound Alberti (ed.), op. cit., note 12 above, pp. 1-23.

${ }^{30}$ As Edwin Clarke and Stephen Jacyna have shown, Galenic models of the nervous system remained in place well into the nineteenth century. Not until the end of the century were they supplanted by modern ideas about how the "autonomic" nervous system originated-autonomy indicating independence of action, linked to the concept of the reflex. See Edwin Clarke and L S Jacyna, Nineteenthcentury origins of neuroscientific concepts, Berkeley, University of California Press, 1987, p. 317.

${ }^{31}$ For a detailed discussion of humoral theory, see Bound Alberti, op. cit., note 29 above.
}

\footnotetext{
${ }^{32}$ Ibid. In theory this was a genderless process, although the types of emotion experienced were gendered, as men and women were naturally subject, as a result of their constitutional differences, to discretely different emotions. Moreover the organ itself was implicitly gendered; Robert Erickson has shown that the heart was often invoked as a masculine and phallic organ. See Robert Erickson, The language of the heart, 1600-1750, Philadelphia, University of Pennsylvania Press, 1997. Kirstie Blair has detailed the shift back towards women in gendering the Victorian heart, with its associated qualities of emotionalism, responsiveness and sympathy. See Blair, op. cit., note 7 above, p. 11.

${ }^{33}$ John Coakley Lettsom, The works of John Fothergill, London, Charles Dilly, 1784, p. 375
} 


\section{Emotions and Heart Disease in the Nineteenth Century}

regimental habits that included sleep, exercise, diet, air, excretions and passions of the mind-balance and moderation in all things was necessary for a peaceful and healthy existence. ${ }^{34}$ Although at the time of Fothergill's writing, fluid-based conceptions of mind/ body interaction were becoming outmoded in favour of hydrodynamic or nervous theories that emphasized the solids, rather than the fluids, of the body, the symbolic and physical status of the heart as mediator of the passions remained intact. ${ }^{35}$ Preventing and treating cardiac dysfunction in the eighteenth century meant a focus on the maintenance of emotional and physical equilibrium. And though this was pertinent to all forms of heart disease, there was something distinctive about angina pectoris that demanded attention. In part this reflected the disease's contemporary status, famously identified by the successful London physician William Heberden in 1772 as a highly specific form of heart disease with a unique symptomology. ${ }^{36}$

\section{The Invention of Angina Pectoris}

Angina pectoris was one of several diseases of the heart to be identified under late eighteenth-century scientific enquiry. ${ }^{37}$ Unlike others, however, it was characterized by a number of physical and psychological symptoms. Derived from the Latin and meaning spasmodic and choking or suffocating pain ("angina") and associated with the chest ("pectoris"), angina pectoris was characterized by severe chest pain, typically running down one arm, and a "sense of strangling, and anxiety". ${ }^{38}$ Later writers continued this emphasis; Latham described the sensation as "something which is beyond the nature of pain, a sense of dying". ${ }^{39}$ Similarly, in The cyclopaedia of practical medicine (1833), there was said to be "something peculiar in the pain" of angina pectoris, "whatever be its degree, unlike the pain of other parts of the body, and as if it were combined with something of a mental quality. There is a feeling and fear of impending death". ${ }^{40}$ It was this peculiar characteristic of the condition that seemed to demonstrate the importance of emotions to heart function, and that also gave angina pectoris its dramatic social resonance.

By the early nineteenth century, angina pectoris was widely known as a form of heart disease. It was understood to occur predominantly in men, and to be related to exertion

\footnotetext{
${ }^{34}$ On the "non-naturals", see Bound Alberti, op. cit., note 29 above, pp. 3, 15 .

${ }^{35}$ Ibid., p. 5.

${ }^{36}$ For a history of "angina" and its terminology, see John Forbes, Alexander Tweedie and John Conolly (eds), The cyclopaedia of practical medicine, London, Sherwood, Gilbert and Piper, 1833-1855, vol. 1, p. 81. For William Heberden, see his 'Some account of a disorder of the breast', Med. Trans. Coll. Physicians, 1772, 2: 59-67, reprinted in his Commentaries on the history and cure of diseases, $2 \mathrm{nd}$ ed., London, T Payne, 1803.

${ }^{37}$ Other heart diseases were classified from the late eighteenth century, including pericarditis (1799) and endocarditis (1809). See J O Leibowitz, The history of coronary heart disease, London, Wellcome
}

Institute of the History of Medicine, 1970. See also Frederick A Willius and Thomas Keys (eds), Cardiac classics, London, Henry Kipton, 1941; Terence East, The story of heart disease, London, William Dawson, 1958; P R Fleming, A short history of cardiology, Amsterdam, Rodopi, 1997.

${ }^{38}$ Heberden, op. cit., note 36 above, p. 59; Wooley, op. cit., note 13 above, p. 75. On the similar etymological origins of "anxiety" to describe a pressing sensation within the chest, see Bound, op. cit., note 26 above, p. 1407.

${ }^{39}$ Latham, op. cit., note 4 above, vol. 2, p. 364.

${ }^{40}$ Forbes, Tweedie and Conolly (eds), op. cit., note 36 above, p. 82 . 


\section{Fay Bound Alberti}

(both physical and mental), diet and health. Patients were typically struck down after eating or taking exercise, and the disease could develop over several years or-in the case of Thomas Arnold-be immediately fatal. Angina pectoris was also recognized outside medical circles. When Thomas clutched his chest in the early hours of a Sunday morning, his wife Mary was immediately vigilant. Although Thomas had previously reported no heart problems to her, she was aware that his father had died young of heart disease. And when her husband told Mary that his pain "seemed to pass from his chest to his left arm", her "alarm was so much roused from a remembrance of having heard of this in connection with Angina Pectoris, and its fatal consequences" that she insisted Dr Bucknill be summoned at once. ${ }^{41}$

In addition to the well-established symptomology of angina pectoris which, as we have seen, lasted well into the nineteenth century, beliefs about the origin of the disease were initially straightforward. Angina pectoris was a structural disease, prompted by physical or mental exertion that caused physical damage to the heart, particularly the coronary arteries. This claim is directly at odds with Wooley's analysis of angina pectoris as a functional disease, that only gradually, and over the course of the nineteenth and twentieth centuries, became redefined as a structural disorder. ${ }^{42}$

As discussed above, Wooley has argued that heart disease was one of many cardiovascular, gastrointestinal and neurological disorders to be "defined, classified, and then redefined in each succeeding period of clinical medicine" from the seventeenth to the nineteenth century. ${ }^{43}$ Although originating as a functional disease, Wooley claims, angina pectoris was only gradually redefined as a structural disorder by technological discoveriesincluding the measurement of arterial hypertension and cardiac arrhythmias in the nineteenth and twentieth centuries-which underpinned medicine as a scientific discipline. ${ }^{44}$ Wooley's argument is compatible with his broader interpretation of the emergence of modern medicine and the invention of new disease concepts, but, I would suggest, it misunderstands the nature of angina pectoris prior to the mid-nineteenth century, and the complexities of heart disease concepts thereafter.

Firstly, angina pectoris was always associated with structural disease. ${ }^{45}$ Heberden's original identification of angina pectoris in a lecture given in 1768 was initially based on clinical observation rather than pathologic findings. By the time of its publication four years later, however, he was able to refer to the findings of an autopsy performed by John Hunter. On this occasion no significant pathology was found, though the coronary arteries (as Edward Jenner would later observe), were not examined. ${ }^{46}$

These reports spurred others on to make anatomical investigations into its structural basis, however, one of which, the autopsy of John Hunter himself, is discussed in more detail below. If we consider parallel developments in pathological anatomy, and

\footnotetext{
${ }^{41}$ Stanley, op. cit., note 2 above, pp. 656-7.

${ }^{42}$ Wooley, op. cit., note 13 above, p. 67.

${ }^{43}$ Ibid., p. 65.

${ }^{44}$ Ibid., p. 66.

${ }^{45}$ Allen B Weisse, 'The elusive clot: the controversy over coronary thrombosis in myocardial infarction', J. Hist. Med. Allied Sci., 2006, 61 (1): 66-78.
}

\footnotetext{
${ }^{46}$ Heberden Commentaries, op. cit., note 36 above. For a discussion of the original autopsy, with Edward Jenner's reported comments, see Caleb Hillier Parry, An inquiry into the symptoms and causes of the syncope anginosa, commonly called angina pectoris, Bath, R Cruttwell, 1799, p. 6.
} 


\section{Emotions and Heart Disease in the Nineteenth Century}

well-established beliefs about emotions and the heart, moreover, it is clear that the earliest medico-scientific findings supported the structural basis of angina pectoris. Discoveries of heart lesions and physical defects were widely used as evidence of the physical effects of emotional disturbance. In Morgagni's The seats and causes of diseases (1768) for instance, the case was presented of a 64-year-old merchant from Padua-corpulent "though not to excess". Formerly in good health, though prone to rheumatism, the merchant got involved in a disagreement with an associate, "from whence he was seiz'd with very violent affections of the mind, with terror, fear, anger and sadness". ${ }^{47}$ In the days following, the patient suffered from a range of convulsive motions and grew red in complexion. His nerves were affected and he was treated for hypochondria, yet his condition worsened until he died fifteen months later. On examination he was found to have a dilated heart and arteries, caused - according to Morgagni-by the agitation of the passions which produced a "very disturb'd motion of the spirits through the nerves; and in particular those which go to the heart and to that artery". 48

This belief in a physical connection between the heart and the passions (whether conceived in terms of fluids, spirits or nerves), continued unabated throughout the eighteenth and nineteenth centuries, especially in such extreme emotional states as "terror, fear, anger and sadness". ${ }^{49}$ One of the most famous examples, repeatedly cited into the twentieth century, was the death of the surgeon and angina pectoris sufferer John Hunter, who collapsed and died in 1793 after an outburst of anger at a Board meeting. ${ }^{50}$ Hunter was widely believed to have "no command over his temper", displaying rather an "irascibility ... [which] probably served to shorten the duration of his existence". 51 An autopsy revealed structural damage to the arteries which was consistent with this interpretation. Moreover, the likelihood of emotional extremes causing damage to the heart was increased in cases of pre-existing structural weakness. As the Glaswegian anatomist Allan Burns wrote in his Observations (1808), when the "nutrient arteries of the heart are diseased" it took very little for the heart to become "overpowered with blood accumulated in its cavities". Then the pulse would begin to falter, the right ventricle became unable to supply blood into the pulmonary vessels, and "a sense of suffocation" would strike the sufferer. He would then feel "an indescribable anxiety and oppression" as a result of accumulated blood around the chest. ${ }^{52}$

Clearly, angina pectoris was regarded as a structural disease in the eighteenth and early nineteenth centuries. The process identified by Wooley is arguably less connected with the changing status of angina pectoris for practising physicians, but with a growing desire and readiness by nineteenth-century theorists to label diseases as either functional or organic.

\footnotetext{
${ }^{47}$ John Baptist Morgagni, The seats and causes of diseases, investigated by anatomy in 5 books, trans. Benjamin Alexander, London, 1769, vol. 3, bk 5, article 5, p. 504.

${ }^{48}$ Ibid., p. 508.

${ }^{49}$ Ibid., p. 504.

${ }^{50}$ E Home, 'A short account of the author's life', in $\mathrm{J}$ Hunter, A treatise on the blood, inflammation and gun-shot wounds, London, J Richardson for George Nichol, 1794, pp. xiii-lxvii, on p. 1xi. The case of John
}

Hunter is dealt with more fully in my forthcoming book, Matters of the heart, ch. 2 .

${ }^{51}$ Thomas J Pettigrew, 'John Hunter: from the Medical Portrait Gallery', Lancet, 1838-39, ii: $119-20$

${ }^{52}$ Allan Burns, Observations on some of the most frequent and important diseases of the heart, (London, Thomas Bryce, 1809), repr. New York, Hafner, 1964, p. 140 . 


\section{Fay Bound Alberti}

This readiness was arguably legitimized, at least in part, by disciplinary developments, such as the rise of the mind sciences (in which the emotions were believed to cause only functional symptoms), and facilitated by such innovations in diagnostic analysis as the stethoscope and sphygmograph. As James Hope put it, the signs of organic and inorganic disease became "much more precise and simple, as a consequence of the new lights thrown on particular valvular diagnosis and on inorganic murmurs". 53

And yet there was considerable discussion in medical textbooks and printed casebooks about the nature of angina pectoris well into the mid-nineteenth century. In John Forbes's edited translation of R T H Laënnec's Treatise on the diseases of the chest (1827), for instance, Forbes added a footnote to address the most recent thoughts on angina pectoris. He acknowledged that William Heberden, the physician Caleb Hiller Parry, Allan Burns and others all related angina pectoris to the ossification of the coronary arteries, and that many well known European physicians thought it an organic disease. ${ }^{54}$ For his part, however, Forbes wrote that the palpitations associated with angina pectoris could be "purely nervous", their origin difficult to establish, even with the stethoscope. ${ }^{55}$ Forbes's perspective was increasingly popular; by the late nineteenth century angina pectoris was included in treatises on the heart under such headings as "functional diseases", or "nervous disorders" or the increasingly common term, "cardiac neuroses". 56 This shift in the terms of diagnosis, and in the status of angina pectoris as a disease, is evidence of the increasing tendency of medical theorists to regard most experiences of angina pectoris as, firstly, functional in origin, and secondly, as symptomatic not of any underlying structural disorder, but of some emotional disturbance or neurosis. In the mid-nineteenth century, and at the level of medical practice, however, definitions of angina pectoris, and of functional or structural diseases, remained in flux. To consider this in more detail we need to return to the subject of our case study, and to the body of Thomas Arnold.

\section{The Body of Thomas Arnold}

Thomas Arnold's body was autopsied within forty-eight hours of his death, "the weather being very hot". 57 Like his final conversation with his physician, Thomas's autopsy was included in Latham's Lectures, as one of three case studies intended to illuminate students on the nature of angina pectoris. The autopsy was conducted by Joseph Hodgson (1788-1869), surgeon at the Birmingham General Hospital from 1822, and author of

\footnotetext{
${ }^{53}$ James Hope, A treatise on the diseases of the heart and breast vessels, London J Churchill, 1839, p. 505, cited in Wooley, op. cit., note 13 above, p. 95 .

${ }^{54} \mathrm{R}$ T H Laënnec, A treatise on the diseases of the chest and on mediate auscultation, ed. John Forbes, 2nd ed., London, T \& G Underwood, 1827, p. 577 ftn. Parry's work was influential soon after that of Heberden. See Caleb Hiller Parry, An inquiry into the
}

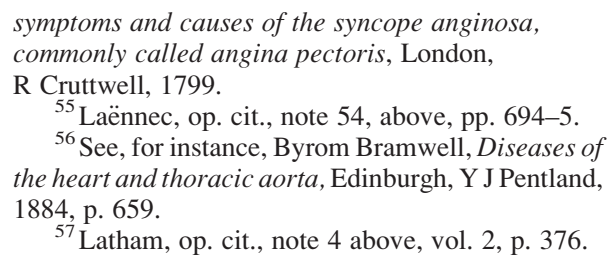

${ }^{56}$ See, for instance, Byrom Bramwell, Diseases of the heart and thoracic aorta, Edinburgh, Y J Pentland, 1884 , p. 659.

${ }^{57}$ Latham, op. cit., note 4 above, vol. 2, p. 376. 


\section{Emotions and Heart Disease in the Nineteenth Century}

Treatise on the diseases of arteries and veins (1815), and witnessed by the junior and senior Drs Bucknill. ${ }^{58}$ On examination, Hodgson found that the pericardium was healthy, but that the heart was "rather large" and "very flaccid and flat in its appearance". There was no indication of valvular disease, and the membranes were healthy. The muscular structure of the heart, however, was "remarkably thin, soft and loose in its structure". The walls of the left ventricle were also "much thinner and softer than usual". 59

Along with the other two cases reported by Latham, Thomas's autopsy showed that structural changes had taken place in the heart; the "muscular substance" being "reduced to an extreme degree of tenuity and softness". ${ }^{60}$ It was clear to Latham that these changes had contributed to the angina in each case. Yet Latham did not believe that evidence of structural change in the heart denoted the organic nature of angina pectoris. He acknowledged that angina pectoris could exist where there was "ossification or obstruction of the coronary arteries", "dilatation of the aorta"; "valvular unsoundness", "hypertrophy or atrophy", or a softening of the heart's muscular substance, as in the case of Thomas Arnold. ${ }^{61}$ Yet Latham maintained that angina pectoris had also been reported where there was "no form of disease or disorganization" either in the heart or its blood vessels. ${ }^{62}$ Moreover, the pain involved in angina pectoris could be misleading, for dangerous heart complaints were not always painful. What this meant for Latham was that angina pectoris was nothing more than a symptom complex: "an assemblage of symptoms" that had been "made to bear the name of a disease". 63

Although angina pectoris was historically identified as an organic disease, then, its symptomology a result of structural changes that were associated with extreme emotions, and lifestyle conditions, including diet and overall health, Latham offered a functional interpretation. Put simply, the "paroxysm of angina pectoris is plainly a compound of pain and something else". The heart ceases to function, perhaps because of a spasm which is in itself the whole disease: "a disease purely vital, a disease of feeling and function alone, operating by and through sound structure, it may be fatally, always perilously" ${ }^{64}$ Unquestionably, Latham acknowledged, the symptoms associated with angina pectoris-the crushing pain in the breast and down one arm, the breathlessness and sense of panic-were widely characteristic, and occurred with sufficient regularity to be identifiable as angina pectoris. Yet, he claimed, they did not amount to any single unity or disease. There were, after all, differences in the structural changes identified in the hearts of his three case studies. And other cases had existed without structural alterations being detected. Although angina pectoris might be independent of organic disease (or produced by it), there was no easy correlation between

\footnotetext{
${ }^{58}$ See Willius and Key (eds), op. cit., note 37 above, p. 114. On Joseph Hodgson, see $O D N B$, vol. 27, pp. 496-7. Thanks to Jonathan Reinarz for valuable discussions of the significance of Hodgson in relation to national and local medical practice.

${ }^{59}$ Latham, op. cit., note 4 above, vol. 2, p. 377.

${ }^{60}$ Ibid., p. 379.
}

\footnotetext{
${ }^{61}$ Ibid., p. 361.

${ }^{62}$ Ibid., p. 362.

${ }^{63}$ Ibid., p. 361. This theme would recur throughout the century, being addressed by many physicians in the nineteenth century, and by William Osler in the twentieth century.

${ }^{64}$ Ibid., pp. 385, 386-7.
} 


\section{Fay Bound Alberti}

the two. ${ }^{65}$ Angina pectoris was a spasmodic attack that could be linked to structural change, but was not detachable from the general systemic health of an individual.

To avoid angina pectoris, and to some extent all forms of heart disease, Latham advised, one needed to take care of the "whole vascular system". For the "spasm" that had been so long identified as a disease could be "put off" and its "severity mitigated" by "no means more surely than by keeping the vascular system in a just balance between fulness and emptiness, between rich blood and poor blood". Of course, there would always be those individuals who - in similar tones to humoral physiology-possessed a natural balance with which they were "very happily born", but for most "a small habitual deviation on this side or that is readily felt and resented by the heart, when it has undergone some form of unsoundness rendering it obnoxious to spasm". 66

What, then, are the implications of Latham's analysis for our historical understanding of angina pectoris and the case of Thomas Arnold? Much of the identification of nineteenth-century scientific medical culture presupposes the emergence of the heart as an objectified muscle that was subject to measurement and classification; a unitary entity that gave rise to its own specialism - cardiology proper-by the early twentieth century. And yet, Latham, one of the acknowledged fathers of modern cardiology, identified the heart as part of an holistic system. In the same spirit and with the same precision that eighteenth-century physicians recommended a strict adherence to the non-naturals, Latham advised patients to monitor their general lifestyles, to control the kind of food and drink taken, ensure sufficient sleep, avoid "troublesome wants such as frequent micturation", and use only moderate physical exertion. Finally, the "passions and affections of the mind" must be regulated, for more than any other cause they produce "fatal attacks of the paroxysm". 67 A similar course of action was taken by Thomas's son Matthew Arnold, in avoiding the onset of angina pectoris. In a letter to his son Richard Penrose, Matthew complained in 1885 that his physician, Andrew Clark, had put him on the "strictest of diets for one week-no medicine, but soup, sweet things, fruit, and worst of all, all green vegetables entirely forbidden, and my liquors confined to one small half-glass of brandy with cold water, at dinner". 68

In his treatment of Thomas Arnold, the physician Bucknill also followed traditional prescriptives for the improvement of circulation and heart function. Firstly, Bucknill ordered that Thomas be given hot strong brandy and water. He also arranged for a mustard plaster to be placed on Thomas's chest. Traditionally mustard plasters were applied to stimulate the internal organs and assist respiration. While the mustard plaster was prepared, Bucknill himself applied hot flannels to Thomas's chest, while the patient's legs and arms were "rubbed" by an assistant. Thomas's feet were then tightly wrapped in flannels that had been soaked in the hot water and mustard mixture. The treatment seemed to be effective, as Thomas's pulse became "natural", his arms and legs were warmer, and he was temporarily free from pain.

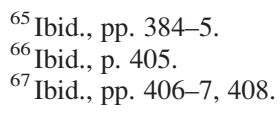

\footnotetext{
${ }^{68}$ Matthew Arnold, Selected letters of Matthew Arnold, ed. Clinton Machann and Forrest D Burt, London, Macmillan, 1993, p. 283.
} 


\section{Emotions and Heart Disease in the Nineteenth Century}

There is no evidence that Bucknill believed his attention would cure Thomas's disease, or do anything more than temporarily alleviate his symptoms. The published record of this encounter suggests a pessimistic tone to the proceedings, with Bucknill acknowledging that painful spasms often returned as swiftly as they had departed, and that such symptoms were usually fatal. What is relevant here, however, is that the therapeutic strategies undertaken by Bucknill, and recommended elsewhere by Latham and others, were primarily aimed at soothing the patient, at increasing his temperature and at encouraging the circulation of the blood. The pharmacological remedies used by Bucknill were also traditionalfirstly, laudanum (an opiate) to relieve Thomas's physical pain, and camphor, often used as a local anaesthetic. More significantly, perhaps, Bucknill also turned to Hoffman's anodyne, essentially the spirit of ether, which was widely used to stimulate a weak heart after Friedrich Hoffman's hydrodynamical investigations in the eighteenth century. ${ }^{69}$ Digitalis, derived from the foxglove and widely believed to be used as a remedy for heart complaints by the early nineteenth century, was not used.

\section{Conclusions}

This article has shown how important emotion beliefs were to the diagnosis and treatment of heart disease in mid-nineteenth-century British culture. It has traced the evolution of angina pectoris as a disease since its eighteenth-century conception, and the role of emotions in causing structural change to the organ of the heart. In the process, it has demonstrated that many of the historiographical claims made about the heart overlook the complexities of structural and functional disease, and the preservation of traditional theories of mind and body interaction. Explicit in the interpretation of angina pectoris offered by Latham, and implicit in Bucknill's treatment of Thomas Arnold, we find the heart's dependence on the entire bodily system. In the mid-nineteenth century as in the eighteenth, it was taken for granted that the emotions could rouse the heart to "tumultuous and irregular action", ${ }^{70}$ or that a weakness elsewhere in the body, such as the digestive system, could cause emotional distress by deranging and corroding the nervous and vascular systems. ${ }^{71}$ Nineteenth-century concepts of nervous disorder replaced hydrodynamical principles in explaining how emotional disturbances produced changes in heart function. And although it was not until the end of the century that its meaning was formalized through neuroscientific investigation, the ancient doctrine of "sympathy" helped to explain the nervous system's influence by the theory of connecting parts. 72

\footnotetext{
${ }^{69}$ Latham, op. cit., note 4 above, pp. 374, 376.

${ }^{70}$ Ibid., p. 412.

${ }^{71}$ Bound Alberti, op. cit., note 29 above, pp. 12-15.

${ }^{72}$ The earliest $O E D$ reference to "sympathy" dates from 1579, and refers to such "sympathia" between "the bodye and the soule, that if either exceede the meane, the one suffereth with the other".
}

In 1655 Nicholas Culpepper also referred to "sympathy or consent from other parts". See $O E D$. By the nineteenth century the doctrine of "sympathy" had taken on a more specific materialistic meaning. On the scientific development of concepts of sympathy, see Clarke and Jacyna, op. cit., note 30 above, p. 102 . 


\section{Fay Bound Alberti}

In the work of Latham, Burns, Corvisart and others, the heart is visualized as the centre of an elaborate network of connections in which the "general life, and individual life of each organ, and part, have a necessary dependence on the life and action of the heart; derange this action, and the derangement must pervade every part of the animal economy". ${ }^{73}$ Therapeutic recommendations, such as Ralph Alderson's Chemical analysis and medical treatise on the Shap Spaw (1828), stressed that this sympathetic intercourse between the heart and other organs of the body meant that such symptoms as violent palpitations, irregular beating of the carotids and acute pain in the chest could be attributed to "a deranged stomach and the effect of wrong living", curable by "abstinence, alteratives, and exertion of body". 74

As these theorists focused on the literal transmission of the heart's experiences through the complex structure of the nerves linking the brain, the heart, and the entire nervous system, invocations to sympathy in nineteenth-century texts took on a meaning far beyond that of affective engagement between individuals. ${ }^{75}$ Several textbooks sought to demonstrate the exact physiological process by which emotion disturbed the heart. In Diseases of the heart and thoracic aorta (1884), for instance, Byrom Bramwell, lecturer in medicine at the University of Edinburgh and pathologist at the Edinburgh Royal Infirmary, explained how the heart was excited "through the agency of the accelerator nerves", stimulated in turn by diminished blood pressure in the cranium. ${ }^{76}$ What mattered here, Bramwell maintained, were the not yet understood movements of the sympathetic system, through which the heart was "intimately connected" through the nerves to the whole of the body. ${ }^{77}$ With the subsequent emergence of the autonomic nervous system, these investigations into the links between the heart and the brain would help to shape and redefine the nature of functional diseases well into the twentieth century. ${ }^{78}$

In the years following Latham's reinterpretation of angina pectoris-as a cluster of symptoms rather than a disease-other physicians followed suit. Many of the general complaints that had been associated with angina pectoris did receive specific and structural diagnoses ("cardiac asthma", for instance, becoming identified as "cardiac dyspnoea"). Angina pectoris became little more than a shorthand for the symptoms associated with the disorder. ${ }^{79}$ In 1836 John Calthorp Williams had suggested that functional symptoms, most notably palpitations, could be divided into two groups: "cardiac or primary palpitation, which resulted from disorders directly affecting the heart; and nervous-sympathetic palpitation associated with 'derangements' affecting the heart through 'nervous sympathy"'.

\footnotetext{
${ }^{73}$ Corvisart, op. cit., note 11 above, p. 31.

${ }^{74}$ Ralph Alderson, A chemical analysis and medical treatise on the Shap Spaw in Westmoreland, Kendal, R Lough, 1828, p. 55.

${ }^{75}$ This is how the term is used by Blair, op. cit., note 7 above, p. 6.

${ }^{76}$ Bramwell, op. cit., note 56 above, p. 38.

${ }^{77}$ Ibid., pp. 16, 38-9. See also Elizabeth A Williams, The physical and the moral: anthropology, physiology and philosophical medicine in France, 1750-1850, Cambridge University Press, 1994, p. 50; Clarke and Jacyna, op. cit., note 30 above.
}

\footnotetext{
${ }^{78}$ Lawrence, “"Definite and material”, , op. cit., note 13 above, and Lawrence, 'Moderns and ancients', op. cit., note 13 above. Clark and Jacyna have shown how important research into the nervous system was in early-nineteenth-century physiology, and the stakes were high, partly because debates focused on the location of mind, but also because they impacted upon similar debates in philosophy and theology. See op. cit., note 30 above, p. 6.

${ }^{79}$ William Osler, Lectures on angina pectoris and allied states, New York, D Appleton, 1897, p. 10
} 


\section{Emotions and Heart Disease in the Nineteenth Century}

In the latter instance, a "morbid irritability" of the nervous system became symptomatic with the symptoms of angina pectoris. ${ }^{80}$

This interpretation was later echoed by the influential Canadian physician William Osler. In 1897 Osler rejected many of the classifications of angina pectoris that had been established a century before by William Heberden. In so doing he redefined angina pectoris not as a disease, but as a "syndrome or symptom group (without constant aetiological or anatomical foundations)" that was associated with the heart and aorta. ${ }^{81}$ The term "angina pectoris" became used to describe "pain about the heart of an agonizing character" that was associated with a range of "organic and functional" conditions. "Used to define paroxysmal attacks of pain in the chest", Osler continued, "we employ the term generically, qualifying the varieties by such names as true, false, hysterical, and vosomotor." 82 Here we have an example of the transformation of "functionalism" by the end of the nineteenth century, to be associated not with disturbances of function, but with hypochondria and neuroses. At the same time, however, Osler referred to "true" angina pectoris, echoing eighteenth-century physicians by defining it as a structural disease of the heart, primarily associated with damage to the coronary arteries. ${ }^{83}$ By the late nineteenth and early twentieth centuries, then, much of the uncertainty over the meanings of functional and structural diseases of the heart was resolved. Angina pectoris became identified as a symptom complex rather than a disease in its own right, though debates over the existence of "true" angina pectoris continued. And many of the functional symptoms associated with angina pectoris (palpitations, arrhythmia) were redefined as imagined or neurotic in nature.

In sum then, mid- to late-nineteenth-century redefinitions of angina pectoris cannot be understood without consideration of the shifting status of emotions as they impacted on the structure or function of the heart. Too often emotions are considered in isolation in history, rather than being embedded in their cultural and epistemological contexts. As this article has shown, emotions have long been relevant to medical history and to interpretations of health and disease. As mediators between mind and body, between the subjective and the objective realms, they are embodied entities that take meaning from a variety of contexts. By the end of the nineteenth century, emotional influence was regarded as functional rather than structural as a result of developments in neuroscience and the theoretical acceptance of concepts of neurosis. In the case of Thomas Arnold, and in definitions of angina pectoris in the mid-nineteenth century, however, emotions were capable of impacting negatively on the whole body system.

As Christopher Lawrence and George Weisz have recently argued, the survival of such medical holism challenges our preconceived ideas about the predominance of "scientific" rationalism in nineteenth-century medicine. ${ }^{84}$ Yet it perhaps also has relevance for our

\footnotetext{
${ }^{80}$ John Calthorp Williams, Practical observations on nervous and sympathetic palpation of the heart, London, Longman, Rees, Orme, Browne, 1836,

p. 100, cited in Wooley, op. cit., note 13 above, p. 98.

${ }^{81}$ Osler, op. cit., note 79 above, p. 8.

${ }^{82}$ Ibid.

${ }^{83}$ There is insufficient space to discuss this here, though it will be addressed in my forthcoming
}

monograph, The heart and the matter. For an example of late-nineteenth- and early-twentieth-century discussions surrounding the status of angina pectoris, see The British Journal of Nursing, Jan. 18, 1908, pp. 42-3.

${ }^{84}$ See Lawrence and Weisz, 'Medical holism', op. cit., note 19 above. 
own understandings of the heart and the emotions, and illuminates the long tradition of medical writings about emotional influence on the heart as an organ in the modern west, when classical accounts of mind/body relation are mainly metaphorical. ${ }^{85}$ For in the present day it is well established that cardiac dysfunction can be a product of emotional disturbances, whether long-term (in diagnoses of stress and anxiety) or short-term, as a result of shock.

${ }^{85}$ See Fay Bound Alberti, 'The emotional heart', in James Peto (ed.), The heart, New Haven, Yale University Press, 2007, pp. 125-42. 